\title{
Noise-optimized virtual monoenergetic imaging technology of the third-generation dual-source computed tomography and its clinical applications
}

\author{
Yanwei Zeng ${ }^{1,2,3}$, Daoying Geng ${ }^{1,2,3}$, Jun Zhang ${ }^{1,2,3}$ \\ ${ }^{1}$ Department of Radiology, Huashan Hospital, Fudan University, Shanghai, China; ${ }^{2}$ Institute of Functional and Molecular Medical Imaging, Fudan \\ University, Shanghai, China; ${ }^{3}$ Center for Shanghai Intelligent Imaging for Critical Brain Diseases Engineering and Technology Research, Shanghai, \\ China
}

Contributions: (I) Conception and design: J Zhang, D Geng; (II) Administrative support: J Zhang, D Geng; (III) Provision of study materials or patients: J Zhang, D Geng; (IV) Collection and assembly of data: Y Zeng; (V) Data analysis and interpretation: Y Zeng; (VI) Manuscript writing: All authors; (VII) Final approval of manuscript: All authors.

Correspondence to: Jun Zhang. Department of Radiology, Huashan Hospital, Fudan University, No. 12 Wulumuqi Road (Middle), Shanghai 200040, China. Email: zhj81828@163.com.

\begin{abstract}
The third-generation dual-source computed tomography (DSCT) is among the most advanced imaging methods. It employs noise-optimized virtual monoenergetic imaging (VMI+) technology. It uses the frequency-split method to extract high-contrast image information from low-energy images and low-noise information from images reconstructed at an optimal energy level, combining them to obtain the final image with improved quality. This review is the first to summarize the results of clinical studies that primarily and recently evaluated the $\mathrm{VMI}+$ technique based on tumor, blood vessel, and other lesion classification. We aim to assist radiologists in quickly selecting the appropriate energy level when performing image reconstruction for superior image quality in clinical work and providing several ideas for future scientific research of the $\mathrm{VMI}+$ technique. Presently, VMI+ reconstruction is mostly used for images of various tumors or blood vessels, including coronary plaques, coronary stents, deep vein thromboses, pulmonary embolisms (PEs), active arterial hemorrhages, and endoleaks after endovascular aneurysm repair. In addition, VMI+ has been used for imaging children's heads, liver lesions, pancreatic lacerations, and reducing metal artifacts. Regarding the reconstruction at the optimal energy level, the VMI+ technique yielded a higher image quality than the pre-optimized virtual monoenergetic imaging (VMI) technique and single-energy CT. Moreover, either low concentrations of contrast medium or low iodine injection rates can be applied before VMI+ reconstruction at a low-energy level to reduce contrast agent-related kidney injury risk. After reconstructing an image at the optimal energy level, both the image's window width and level can also be adjusted to improve the image effect's reach and diagnosis suitability. To improve image quality and lesion-imaging clarity and reduce the use of contrast agents, VMI+ reconstruction technology has been applied clinically, in which the selection of energy level is the key to the whole reconstruction process. Our review summarizes these optimal levels for radiologists' reference and suggests new ideas for the direction of future VMI+ research.
\end{abstract}

Keywords: Dual energy scanned projection radiography; X-ray computerized tomography; tumor; blood vessel

Submitted Oct 24, 2020. Accepted for publication Jun 02, 2021.

doi: 10.21037 /qims-20-1196

View this article at: https://dx.doi.org/10.21037/qims-20-1196 


\section{Introduction}

With the advancement of medical imaging, lowering the radiation dose and improving image quality have become focuses of CT innovation. Dual-energy CT (DECT) as an advanced CT technology is now widely used in clinical practice. It can help distinguish between different material compositions by evaluating differences in the attenuation of radiation of two different energies passing through them (1). Moreover, this principle is applied to different algorithms and postprocessing methods, including virtual monoenergetic imaging (VMI), effective atomic number and electron density map, material decomposition [including the virtual non-contrast (VNC) imaging, iodine map (IM), and lung ventilation map], and the material differentiation or labeling (including the urinary stone component analysis, gout imaging, bone removal, pulmonary vascular analysis, and material prominence) (2). Virtual monoenergetic (VM) images-which are reconstructed in the imagedomain by the linear combination of two image series; one generated at a high energy level and another generated at a low energy level—can be used as conventional diagnostic images. The VM images show higher iodine contrast at a low energy level and fewer metal artifacts at a high energy level than single-energy CT (SECT) and linearly blended images (3); however, the low penetration ability of low-energy X-ray photons leads to the generation of large noise on VMI reconstructions, thus limiting VMI use. Recently, a reconstruction technique for the thirdgeneration dual-source CT (DSCT)-i.e., noise-optimized virtual monoenergetic imaging (VMI+) — was developed. It uses a frequency-split method to obtain high-contrast image information from low-keV images and high spatial frequencies with the lowest noise information on the optimal-keV images, ultimately combining them to obtain a series of high-contrast and low-noise images (4). The application of the VMI+ technique has significantly resolved the problem of image noise-largely produced at low energy levels - and is a new postprocessing technique for radiological diagnosis. At present, the summary of VMI+ technology is mostly mentioned in the review of the research progress of DECT, and it is only briefly introduced. To acquire better image quality, assist radiologists in applying more appropriate energy levels for reconstruction, and provide more scientific research ideas for VMI+ technology, this review is the first to summarize the results of recent clinical studies for VMI+ technology. The similarity of reconstruction conditions under the same lesion type, such

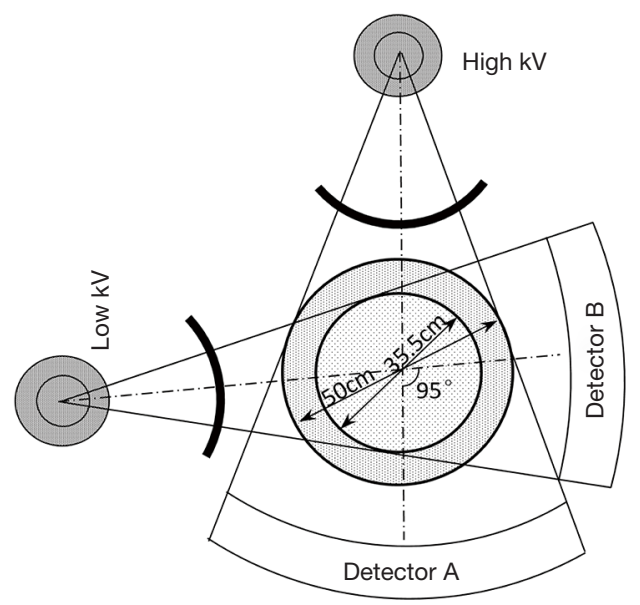

Figure 1 The dual-source computed tomography (DSCT) has two sets of X-ray tube and detector, which are independent in structure and interrelated in data. The two combinations are set at an angle of about 95 degrees on the third generation DSCT. The A tube and detector have a $50 \mathrm{~cm}$ diameter scan field of view, and B has a smaller $35.5 \mathrm{~cm}$ diameter scan field of view.

as tumors or vessels, is highlighted. Lastly, all optimal energy levels for VMI+ reconstruction recommended in these studies are summarized to guide clinical applications.

\section{Development of $\mathrm{VMI}+$ reconstructions}

\section{DSCT}

In 1973, Hounsfield reported that the estimation of atomic numbers of materials and differentiation of materials with different atomic numbers could be possible using two pictures acquired at different energy levels (5). Subsequently, several researchers performed a preliminary exploration of DECT application (6-11). Until the first DECT (Somatom Definition DS) was produced in 2006, the popularity of SECT was not affected. Unlike the singlesource DECT, including rapid $\mathrm{kVp}$ switching CT, duallayer spectral detector CT, and twin-beam CT, the DECT is a DSCT scanner with two independent $\mathrm{X}$-ray tubes and two corresponding detectors; furthermore, the currents and voltages of both tubes are independently regulated (Figure 1). Therefore, radiations of different energies can be generated from the two tubes, and the obtained attenuation information of the material can be utilized to identify the compositions of materials. In addition, the use of both tubes can maximize spectral separation and reduce radiation dose $(2,12,13)$. 
Moreover, with both tubes arranged at almost right angles in a plane, DSCT can show improved time resolution compared to SECT. The most advanced DSCT scanner-the third-generation DSCT (Somatom Force)shows a broader spectrum separation than DSCT scanners of preceding generations, showing the maximum spectrum separation at $70 \mathrm{kVp} / 150 \mathrm{Sn} \mathrm{kVp}$ (tube potential pair). Applying maximum spectrum separation can improve the imaging quality of small body parts, such as the extremities of adults and children, and parts of children's bodies (2). In addition, the tin filter of the high-energy tube can widen the spectrum separation by blocking the filtration of lowenergy photons, thus increasing the effective energy and reducing ineffective radiation simultaneously. Furthermore, the third-generation DSCT scanner widens the scanning field of the low-energy tube to avoid the loss of imaging information of patients with obesity, a concern with DSCT scanners of preceding generations (14).

\section{VMI}

Ideally, the high- and low-energy radiations from both X-ray tubes should be composed of monochromatic photons. In reality, the X-ray spectrum is polychromatic, which can produce image noise and beam-hardening or metal artifacts because of the difference in the absorption of photons by different materials; that is, materials with high attenuation coefficient absorb more low-energy than high-energy photons. Nevertheless, a series of monochromatic images can be simulated by linearly combining two series of images, each generated at one of the two energy levels of single- or dual-source DECT; this technology is called VMI $(1,3,15)$. Therefore, VMI combines the features of images acquired both at high and low energy levels. At high energy, the VMI reconstruction has the advantages of reduced image noise and metal artifacts $(3,14)$. Although the Compton scattering and the photoelectric effect are both involved in the interaction of $\mathrm{X}$-rays with materials, the photoelectric effect is dominantly involved at low energy levels, and only a few heavy atoms show a strong photoelectric effect. Moreover, the average photon energy is close to the K-edge of iodine at a low energy level. Combining the two effects significantly increases the attenuation and improves the contrast of iodine at low energy $(1,2,16)$. Yu et al. reported that the average attenuation of iodine was $70 \%$ higher at $60 \mathrm{keV}$ (about $80 \mathrm{kVp}$ ) than at $77 \mathrm{keV}$ (about $120 \mathrm{kVp}$ ) $(16,17)$. However, during VMI, the low penetration capability of low-energy $\mathrm{X}$-ray photons is associated with higher imaging noise on DECT compared to SECT scanning. Although the contrast of iodine is increased, it does not necessarily improve the contrast-to-noise ratio (CNR) $(3,18)$.

\section{VMI+}

To reduce image noise and improve the CNR of iodine, Grant et al. (4) improved the VMI technique. They used the frequency-split method to extract the desired frequency information from two sets of images acquired at low and optimal energy levels for VMI reconstructions and subsequently combined them to produce a new series of images of the same frequency showing the characteristics of high-contrast and low-noise. In this study, despite the presence of low-noise which still may affect the image quality at low energy levels for the VMI+ reconstructions, it was demonstrated that CNRs of lesion models were significantly higher than for VMI reconstructions, especially at $40 \mathrm{keV}$, which is lower than the previously reported energy levels $(60-70 \mathrm{keV})$ associated with the highest CNR for VMI reconstructions. The VMI+ technique helps achieve high contrast with low doses of iodine and without obvious image noise at low energy levels and reduces the beam-hardening and photon starvation artifacts caused by high attenuation materials at high energy levels. It has been a better reconstruction method than has been VMI for radiological diagnosis.

\section{Clinical studies and applications}

The VMI+ technique is commonly applied to images of tumors and vessels containing contrast medium, and several studies have demonstrated that VMI+ reconstructions show better quality and more clinical values than VMI and linearly blended reconstructions.

\section{Tumor}

In the studies on contrast-enhanced imaging of tumors, the highest signal-to-noise ratio (SNR) and CNR of most lesions were both observed when $40 \mathrm{keV}$ VMI+ was used; these values were higher than those of VMI+ reconstructions of other energy levels, all VMI series, and linearly blended (M_0.6, M_0.3, and so on) images, and decreased gradually with an increase in energy levels. However, the energy levels required for the best subjective evaluation are approximately $50-60 \mathrm{keV}$. This was possibly 
due to the occurrence of the highest image noise at $40 \mathrm{keV}$ and because of its gradual decrease with an increase in energy level. Therefore, although the SNR or CNR of the images is the highest at the lowest energy level, the subjective preference of observers is still affected by image noise, and relatively higher energy levels are preferred for the best subjective evaluation. In all studies, the optimal energy levels for VMI+ reconstructions recommended by researchers for different tumors were typically in the range of 50-60 keV. The optimal energy levels of reconstruction recommended for various cancers/tumors are as follows: $50 \mathrm{keV}$ for cutaneous malignant melanomas and renal cell carcinomas (RCCs) in the corticomedullary-phase of enhancement $(19,20) ; 55 \mathrm{keV}$ for head and neck cancers, lung cancers, and hypervascular liver tumors (21-23); $60 \mathrm{keV}$ for RCCs in the nephrogenic-phase of enhancement, gastrointestinal stromal tumors, and abdominal metastases, and hypo-attenuating liver metastases from colorectal cancers $(19,24,25)$; low energy levels especially 40 and $50 \mathrm{keV}$ for pancreatic adenocarcinomas (26); and $40 \mathrm{keV}$ (a small number of studies) for malignant tumors in the head and neck region, metastatic spinal tumors, and early gastric cancer (27-30). Concerning head and neck malignancies, Albrecht et al. found that $55 \mathrm{keV}$ reconstructions could yield the best subjective image quality (21); however, May et al. recommended $40 \mathrm{keV}$ for optimal image quality (28). The source of this difference may be the subjective inconsistency among different evaluators. Therefore, the optimal energy level for the reconstruction of head and neck malignancy images may be determined through further studies.

Some studies reported interesting findings. Martin et al. (19) analyzed the reconstruction images of RCC during the corticomedullary and nephrogenic phases of enhancement and recommended energy levels for each of the phases. Shi et al. (29) found that the proportion of focal enhanced lesions of early gastric cancer in the portal phase displayed in $\mathrm{VMI}+$ reconstructions was $16.1 \%$ higher than that in mixed $120 \mathrm{kV}$ polyenergetic images (PEIs). Moreover, in VMI+ reconstructions, the superficial- and excavatedtype lesions, which were not visible in the PEIs, could be found, and consequently, observers can stage early gastric cancer more correctly. It was believed that the application of $40 \mathrm{keV} \mathrm{VMI}+$ technology plays a key role in selecting treatment methods because it is associated with a decrease in false staging rate. By simulating liver and hypervascular tumors containing iodine in vitro, Marin et al. (23) found that the tumor-liver CNR was the highest in VMI+ reconstruction regardless of the diameter of the liver and the surrounding fat-mimicking rings. Furthermore, in small, medium, and large models, the highest CNRs of VMI+ reconstructions were $64 \%, 55 \%$, and $69 \%$ higher than those of VMI reconstructions, respectively. Therefore, it was considered that the use of the VMI+ technique could eliminate the need for considering the body size and simplification of the workflow of reconstructions. Although Lukas et al. (25) recommended $60 \mathrm{keV}$ as the optimal energy level of reconstruction for hypo-attenuating liver metastases from colorectal cancer, they believed that the $40 \mathrm{keV} \mathrm{VMI}+$ could provide additional information on lesions with poor contrast and unclear outline. Interestingly, May et al. (28) compared the application of third-generation dual-source DECT and single-source DECT to detect head and neck cancers. They found that dual-source DECT yielded a higher cancer contrast, clearer margin, and superior subjective image quality than single-source DECT.

When the most appropriate energy level is selected, $\mathrm{VMI}+$ reconstructions of tumors during enhancement can show less noise, higher SNR and CNR, and better subjective image quality along with clearer lesions than VMI reconstructions and linearly blended images can (Figure 2); furthermore, selection of the most appropriate energy level may help reduce the impact of patient's body size on image quality and play a key role in the diagnosis and treatment.

\section{Vessels}

$\mathrm{VMI}+$ has often used for the reconstruction of CT angiography (CTA) images.

\section{Cerebral and cervical CTA}

Leithner et al. (31) reported that the VMI+ and VMI reconstruction techniques at an optimal energy level (40 $\mathrm{keV}$ and $60 \mathrm{keV}$, respectively) and the conventional linearly blended (M_0.6) reconstruction techniques did not show differences in the subjective detection and grading of stenosis at the bifurcation of the common carotid arteries (CCA) and the siphon of the internal carotid arteries (ICA). However, researchers believed that additional VMI+ reconstructions could help improve the quality of unclear head and neck CTA images because all vessels show the highest CNRs on these reconstructions. Riffel et al. (32) also reported that ultra-low $\mathrm{keV} \mathrm{VMI}+$ reconstruction could improve the basilar arteries and ICA image quality. Concerning the standard mixed images (similar to the acquisition at $120 \mathrm{kVp}$ ), Zhao et al. (33) found that the attenuations of cerebral and cervical arteries in the $40 \mathrm{keV}$ 

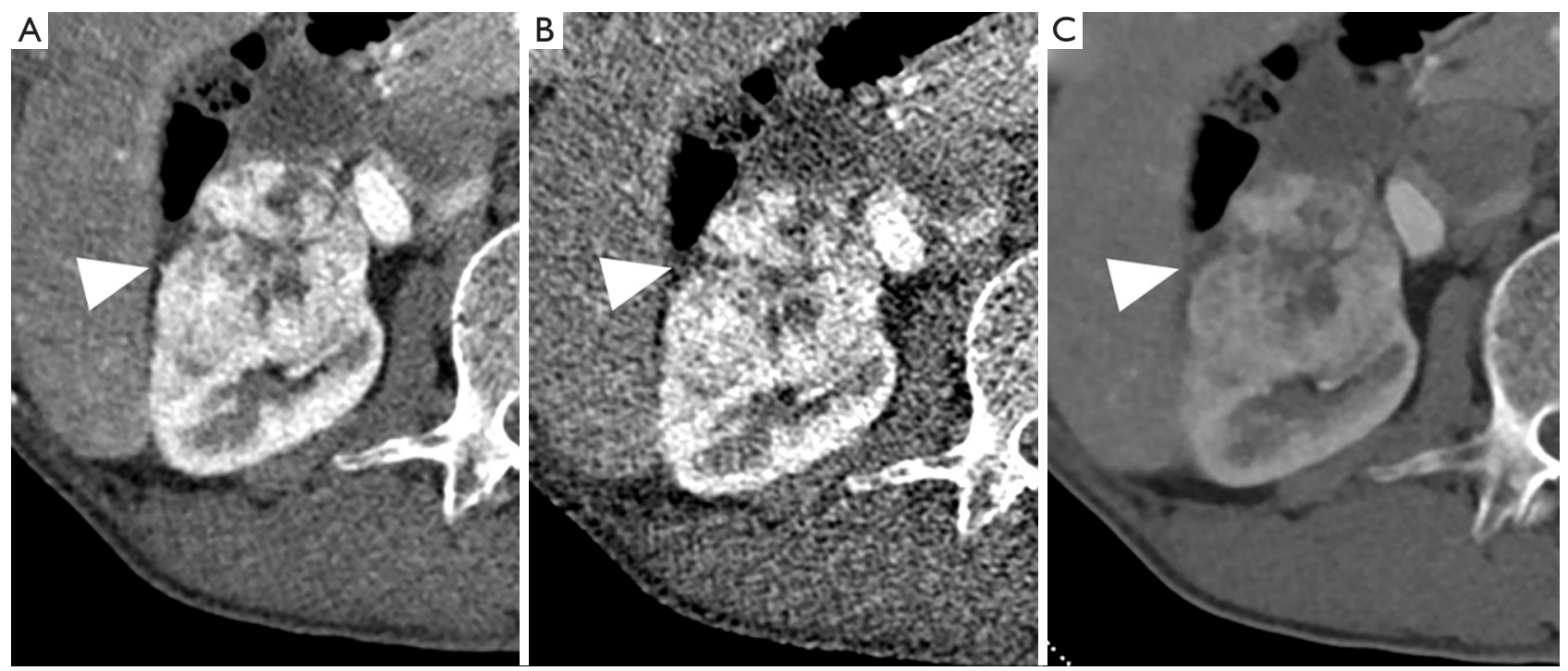

Figure 2 The renal carcinoma (arrowhead) with heterogeneous enhancement in the corticomedullary phase of a 65-year-old male was scanned on the third-generation dual-source computed tomography (DSCT), and the $50 \mathrm{keV} \mathrm{VMI+} \mathrm{(A),} 50 \mathrm{keV}$ VMI (B), and linearly blended (M_0.7, C) images were reconstructed with the same window settings (level/width, 150/600). On the 50 keV VMI+ image, the lesion has the clearest boundary and internal structure, highest attenuation, and less noise. VMI; virtual monoenergetic imaging.

VMI+ reconstructions of the low-concentration contrastmedium group were all significantly higher than those in the high-concentration contrast-medium group; however, the CNRs were similar between the groups. Therefore, it was proposed that a low concentration of contrast medium can be selected before the application of VMI+ technology for the reconstruction of cerebral or cervical CTA images.

\section{Coronary blood vessel}

Arendt et al. (34) found that images of the coronary arteries showed the best subjective and objective quality, including subjective vascular contrast and contour of calcified plaques, at $40 \mathrm{keV}$. Symons et al. (35) analyzed both calcified and non-calcified coronary plaques and found that the CNR of coronary plaques can be improved at low energy levels (40-70 keV); however, they indicated that accurate measurement of the absolute volume of coronary plaques might be difficult at $40 \mathrm{keV}$. Therefore, re-calibration software and observers with abundant diagnostic experience are required when using $40 \mathrm{keV}$ reconstruction. In coronary stent imaging, the presence of beam-hardening artifacts and partial volume effects can cause the underestimation of stent lumen diameter by observers (36). Mangold et al. (37) analyzed coronary stents, but the imaging was in vitro. Their findings were as follows: the highest CNR of in-stent iodine was observed at $120 \mathrm{keV}$, while the maximum in- stent diameter could be measured at $130 \mathrm{keV}$, especially for a diameter of $\leq 3 \mathrm{~mm}$. However, coronary CTA (CCTA) was not generally recommended for evaluating coronary stents in the guidelines (38), and the application of the above finding could expand the usefulness of CCTA for the evaluation of stents, including small stents. Moreover, their study found that the radiation dose of DECT was 49\% lower than that of $120 \mathrm{kV}$ SECT. In addition, De Santis et al. (39) reported that a combination of low iodine delivery rate $(0.4-1.0 \mathrm{gI} / \mathrm{s})$ and $40-70 \mathrm{keV} \mathrm{VMI}+$ reconstructions could help achieve diagnostic attenuation $(300 \mathrm{HU})$ of coronary blood vessels. The possibility of applying low radiation dose using DECT and advantages of using low-concentration contrast agent with low-energy VMI+ reconstruction for obtaining diagnostic images facilitate the wide usage of a combination of DECT and VMI+ for evaluating coronary arteries. In addition to coronary arteries, coronary veins often play an important role in treating heart disease. However, Kim et al. (40) found that the objective and subjective image quality of the conventional linearly blended (M_0.6) reconstruction was better than that of VMI+ reconstruction for coronary veins.

\section{Aorta CTA}

As indicated in the preceding section, Beeres et al. (41) reported that the SNR and CNR of aorta CTA in 
VMI+ reconstructions were higher than those in VMI reconstructions, especially at low energy levels. In addition, Martin et al. (42) analyzed the left ventricular blood pool, infrarenal aorta, iliac and femoral arteries and obtained similar results. Nevertheless, by combining the subjective evaluation of image quality and ability to obtain relevant measurements of the transcatheter aortic valve replacement (TAVR), the researchers recommended 50-60 keV VMI+ as the reconstruction technique for the aorta CTA before TAVR.

\section{Pulmonary CTA}

Concerning pulmonary angiography, Meier et al. observed the highest SNR and CNR of images and the highest subjective image quality score at $40 \mathrm{keV}$ (43); these findings were in contrast with those reported by Martin et al. concerning the aorta (42). Meyer et al. (44) analyzed pulmonary angiography images of patients with suspected pulmonary embolism (PE); they observed the highest $\mathrm{CNR}$ of main pulmonary arteries at $50 \mathrm{keV}$ and peripheral pulmonary arteries at $40 \mathrm{keV}$ extremely high sensitivity, specificity, and accuracy. In addition, $40-50 \mathrm{keV}$ is found to be ideal for image reconstruction when low-dose iodine was used to reduce the risk of renal damage. In addition, $\mathrm{PE}$ could be incidentally found when evaluating tumors in portal-venous phase CT (CTpv) images. According to a study by Weiss et al. (45), low-keV reconstruction can significantly increase the contrast of pulmonary arteries and improve the visibility of occasional pulmonary emboli in CTpv. Their subsequent study, they (46) found volumes of small emboli being occasionally over-amplified at $40 \mathrm{keV}$; this could limit the detection of actual-sized emboli, not being fully compensated for through windowsetting adjustment. However, this study was based on reconstruction at only two energy levels, 40 and $55 \mathrm{keV}$; therefore, $55 \mathrm{keV}$ reconstruction, which yields better results, is recommended. After selecting the appropriate reconstruction level, D'Angelo et al. (47) considered that image quality degradation owing to improper window settings might affect inexperienced observers' ability to interpret images. They recommended $40 \mathrm{keV}$ as the optimal energy level and 1,070/380 as the optimization parameters of window settings for pulmonary angiography.

\section{Bronchial arteries}

Because bronchial arteries are close to the esophagus in the mediastinum, they may be injured during surgery for esophageal cancer, which may cause bleeding. Therefore,
Nomura et al. (48) evaluated the image quality of bronchial arteries on VMI, VMI+, and composite (about $105 \mathrm{kVp}$ ) reconstructions. They found that $40-50 \mathrm{keV}$ VMI may be more suitable for visualizing bronchial arteries and surrounding tissue. The results were considered due to the subjective evaluation affected by the higher CT attenuation on VMI than VMI+ at low voltages. It is suggested that VMI+ may be poor in the display of fine vessels.

\section{Abdominal vessels}

Schabel et al. (49) found that the SNR, CNR, and visibility were the highest at $40 \mathrm{keV}$ on VMI+ reconstructions of hepatic veins and that these values were higher than those of VMI reconstructions and conventional linearly blended (M_0.6) images. Furthermore, Albrecht et al. (50) found that low-keV VMI+ reconstructions show high image quality for hepatic, splenic, superior mesenteric, and renal arteries. In their subsequent study, they (51) increased the number of target arteries of the thorax and abdomen. Their study suggested $70 \mathrm{keV}$ as the optimal energy level for VMI+ reconstruction of thoracoabdominal CTA images and indicated that additional $40 \mathrm{keV}$ or $50 \mathrm{keV} \mathrm{VMI}+$ reconstructions may be necessary when poor vascular contrast or requirements for clearer small vessel images are noted. Martin et al. (52) found that the $40 \mathrm{keV}$ VMI+ reconstruction improved the diagnostic accuracy of active arterial abdominal hemorrhage and recommended $40 \mathrm{keV}$ as the energy level for image reconstruction when abdominal or pelvic vascular hemorrhage is suspected. In addition, Caruso et al. (53) recommended $40 \mathrm{keV}$ as the energy level of reconstruction for obtaining the best CNR and 1,350/430 as the window width and level for obtaining the best quality images of the abdominal aorta and bilateral common iliac and femoral arteries. The window settings were wider and higher than those recommended by D'Angelo et al. (47) for pulmonary angiography.

\section{Lower extremity CTA}

Wichmann et al. (54) analyzed the lower extremity arteries and found that objective image quality, including intravascular contrast attenuation and CNR, was the highest for $40 \mathrm{keV}$ and $50 \mathrm{keV} \mathrm{VMI+;} \mathrm{furthermore,} \mathrm{they} \mathrm{found} \mathrm{that}$ the sensitivity of VMI+ reconstructions for the detection of vascular stenosis was $>50 \%$ higher than that of VMI reconstructions and conventional linearly blended (M_0.6) images. However, their study recommended $50 \mathrm{keV}$ VMI+ for reconstruction due to the higher image noise level at $40 \mathrm{keV}$. 

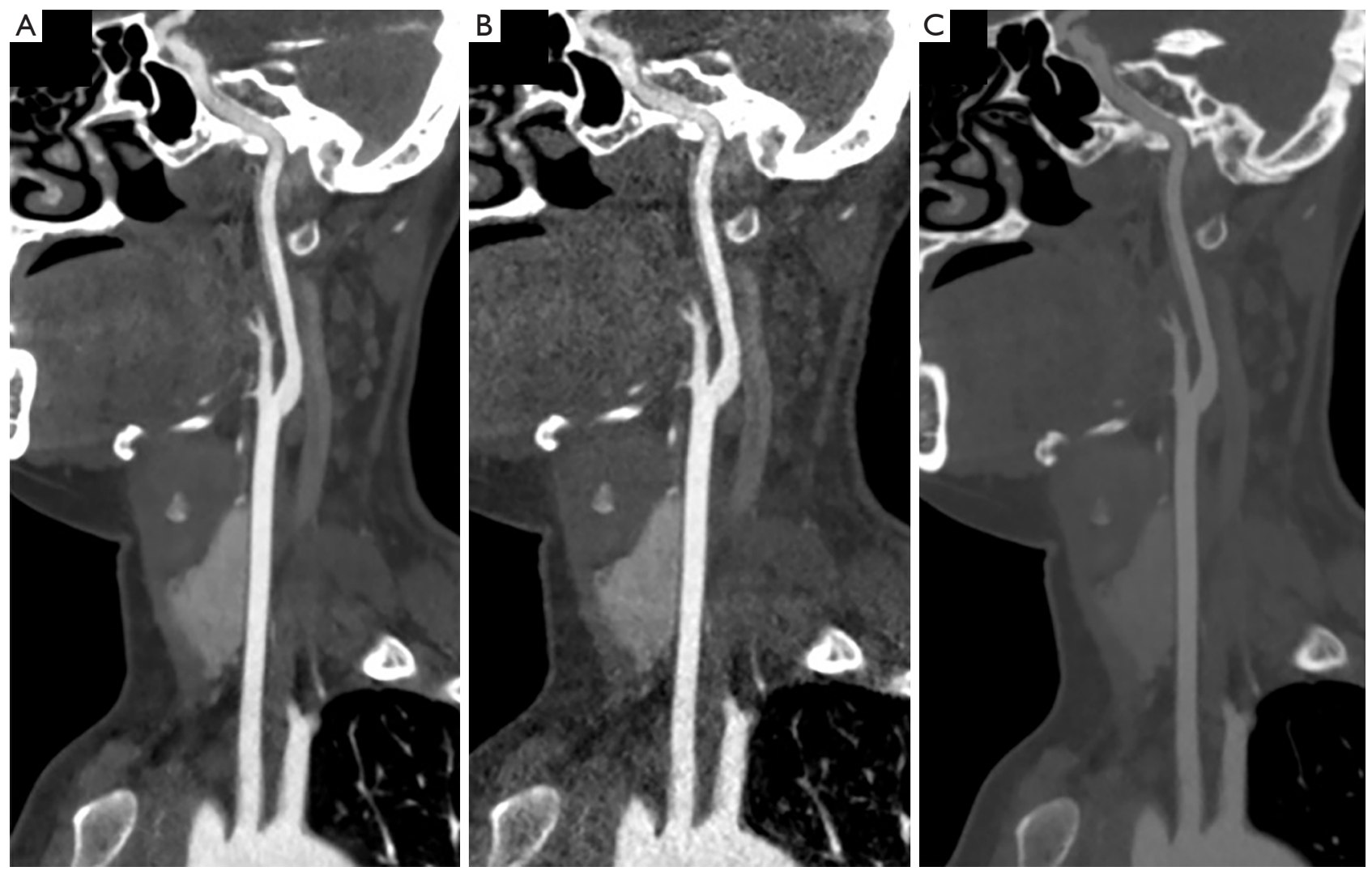

Figure 3 The neck CT angiography (CTA) of a 32-year-old male was scanned on the third-generation dual-source computed tomography (DSCT), and the $40 \mathrm{keV}$ VMI+ (A), $40 \mathrm{keV}$ VMI (B), and linearly blended (M_0.6, C) images were reconstructed with the same window settings (level/width, 500/2,000). The carotid artery showed the best image quality on the $40 \mathrm{keV}$ VMI+ image with the highest contrast attenuation and less noise. VMI, virtual monoenergetic imaging.

\section{Endoleaks after endovascular aneurysm repair (EVAR)} Endoleak, a common complication occurring after EVAR, can increase the rupture of an enlarged aneurysm, with early detection associated with an improved prognosis (55). Martin et al. (56) recommended $40 \mathrm{keV}$ as the best energy level for image reconstruction when concurrent endoleaks are suspected after EVAR surgery.

\section{Venous thrombosis}

Venous thromboembolism, including PE and deep vein thrombosis (DET), gradually increases with the progression of age (57), with CT venography being the preferred diagnostic method. However, because the attenuation of thrombotic substances changes with age, it is difficult to detect thrombosis when its attenuation is close to that of the contrast medium in vessels (58-60). VMI+ reconstruction can help distinguish thrombosis from iodine by enhancing the contrast of the latter. Through in vitro study, Bongers et al. (61) reported that high contrast and CNR of clots in blood samples showing high and intermediate attenuations were observed in $40 \mathrm{keV} \mathrm{VMI}+$ reconstructions, and those in blood samples showing low attenuations were observed in $190 \mathrm{keV}$ VMI+ reconstructions. A low energy level can increase iodine contrast, while a high energy level can reduce iodine contrast; therefore, the contrast difference between blood and clots can be achieved.

As in the case of tumors, SNR or CNR of vessels with iodine contrast was the highest at $40 \mathrm{keV}$ in the VMI+ reconstructions. Nevertheless, based on the subjective evaluation, the recommended energy levels of enhanced vessel reconstruction-which were mostly in the range of $40-50 \mathrm{keV}$-were slightly lower than those for tumors. (The reconstruction images of cervical CTA are shown in Figure 3). This may be due to two reasons: a higher concentration of contrast medium in vessels than tumors and high absorption of low-energy X-rays 
at low energy levels, making the vascular attenuation of thrombosis more obvious than tumors. Nonetheless, at $40 \mathrm{keV}$, the absolute volume of coronary plaques or PE could vary; therefore, either an appropriate correction or using other energy levels are necessary. Moreover, the contrast difference between blood and thrombosis could be changed by adjusting the energy level to facilitate the appropriate visualization of thrombosis. In addition to the intravascular conditions, a low-keV condition of VMI+ reconstruction could facilitate the visualization of vascular bleeding. Furthermore, studies confirmed that low concentrations of contrast medium or low iodine injection rates could also maintain diagnostic requirements of low$\mathrm{keV}$ VMI+ reconstructions. Except for the applications of VMI+ reconstructions at low energy levels, those at the high energy level were proven to be more valuable for the imaging of small coronary stents. After selecting the appropriate energy level for reconstruction, several studies recommend selecting appropriate window width and window level for image observation. A previous study on coronary arteries showed that the radiation dose used for DECT was lower than that for SECT.

\section{Others}

\section{Children's head}

Through quantitative analysis of image quality, including grey and white matter SNR, grey-white matter CNR, and posterior fossa artifact index, as well as through qualitative analysis of overall subjective image quality, supratentorial image noise, grey matter, and white matter differentiation, and posterior fossa artifacts, Park et al. (62) found that except for the least posterior fossa artifacts or the lowest artifact index observed at $70 \mathrm{keV}$, the other objective and subjective evaluations were optimal at $60 \mathrm{keV}$.

\section{Abdomen \\ Suitable tube potential settings for different abdominal sizes}

After inserting cylinders in torso-shaped water phantoms of different diameters in a vitro study, Michalak et al. (63) found that there was no increase in image noise due to iodine at $40 \mathrm{keV}$ using a tube potential pair of $70 \mathrm{kVp} / 150$ $\mathrm{Sn} \mathrm{kVp}$ in phantoms with a diameter of $\leq 35 \mathrm{~cm}$. Moreover, $40 \mathrm{keV}$ can still be used for reconstructing iodine imaging, but the tube potential pair of $80 \mathrm{kVp} / 150 \mathrm{Sn} \mathrm{kVp}$ should be set, and when the diameter is $35-40 \mathrm{~cm}, 50 \mathrm{keV}$ should be used if artifacts are generated. Furthermore, for a $40-45 \mathrm{~cm}$ diameter, the corresponding tube potential should be set at
$90 \mathrm{kVp} / 150 \mathrm{Sn} \mathrm{kVp}$, and the energy level should be set at no less than $60 \mathrm{keV}$. In addition, for a diameter of $>45 \mathrm{~cm}$, the corresponding tube potential, and energy level should be set at $90 \mathrm{kVp} / 150 \mathrm{Sn} \mathrm{kVp}$ and no less than $70 \mathrm{keV}$, respectively.

\section{Hyper-and bypo-attenuating liver lesions}

Husarik et al. (64) analyzed the hyper- and hypoattenuating liver lesions with different concentrations of iodine using phantoms of four different sizes and reported that $40 \mathrm{keV}$ and $190 \mathrm{keV}$ should be the energy levels of reconstructions for hyper-attenuating and hypo-attenuating lesions, respectively; however, they recommended that SECT be selected for imaging lesions in a very obese patient. Interestingly, Caruso et al. (65) analyzed the hypo-enhancing lesions with a diameter of $>1$ $\mathrm{cm}$ in the portal phase and found that although subjective image quality and preference were superior at $50 \mathrm{keV}$, the CNR of lesions was the highest at $40 \mathrm{keV}$, which is contrary to the results reported by Husarik et al. (64), potentially because their liver models (64) contained no iodine. In fact, the iodine content of liver parenchyma is significantly higher than that of the hypo-attenuating lesions in enhanced CT scans; with a decrease in energy level, the degree of increase in liver attenuation is always higher than that of the hypo-attenuating lesions, resulting in the continuous increase of CNR. Furthermore, De Cecco et al. (66) found that $50 \mathrm{keV}$ VMI+ provided superior image quality and diagnostic accuracy for the detection of hypervascular liver lesions, especially those with a diameter of $<1 \mathrm{~cm}$, but the sensitivity and specificity for the detection of lesions with a diameter of $\geq 1 \mathrm{~cm}$ were not significantly higher than those of VMI and linearly blended (M_0.6) reconstructions. Sample DECT reconstruction images of hypo- and hyper-attenuating liver lesions are shown in Figure 4.

\section{Optimum window settings for liver imaging}

De Cecco et al. (67) found that the application of optimal window settings yielded high diagnostic accuracy. They selected $50 \mathrm{keV}$ VMI+, $70 \mathrm{keV}$ VMI, and linearly blended (about $120 \mathrm{kVp}$ ) reconstruction techniques based on prior studies to analyze images of the hepatic arterial and portal phases; they found that the attenuation was the highest at $50 \mathrm{keV} \mathrm{VMI}+$ and that both the optimal window width and level were $429.3 \pm 44.5$ and $129.4 \pm 9.7 \mathrm{HU}$, respectively, in the arterial phase and $376.1 \pm 14.6 \mathrm{HU}$ and $146.6 \pm 7.1 \mathrm{HU}$, respectively, in the portal phase. In addition, for detecting the lesions using $50 \mathrm{keV}$ VMI+, sensitivity was $100 \%$ and $96 \%$ in the arterial and portal phase, respectively. 

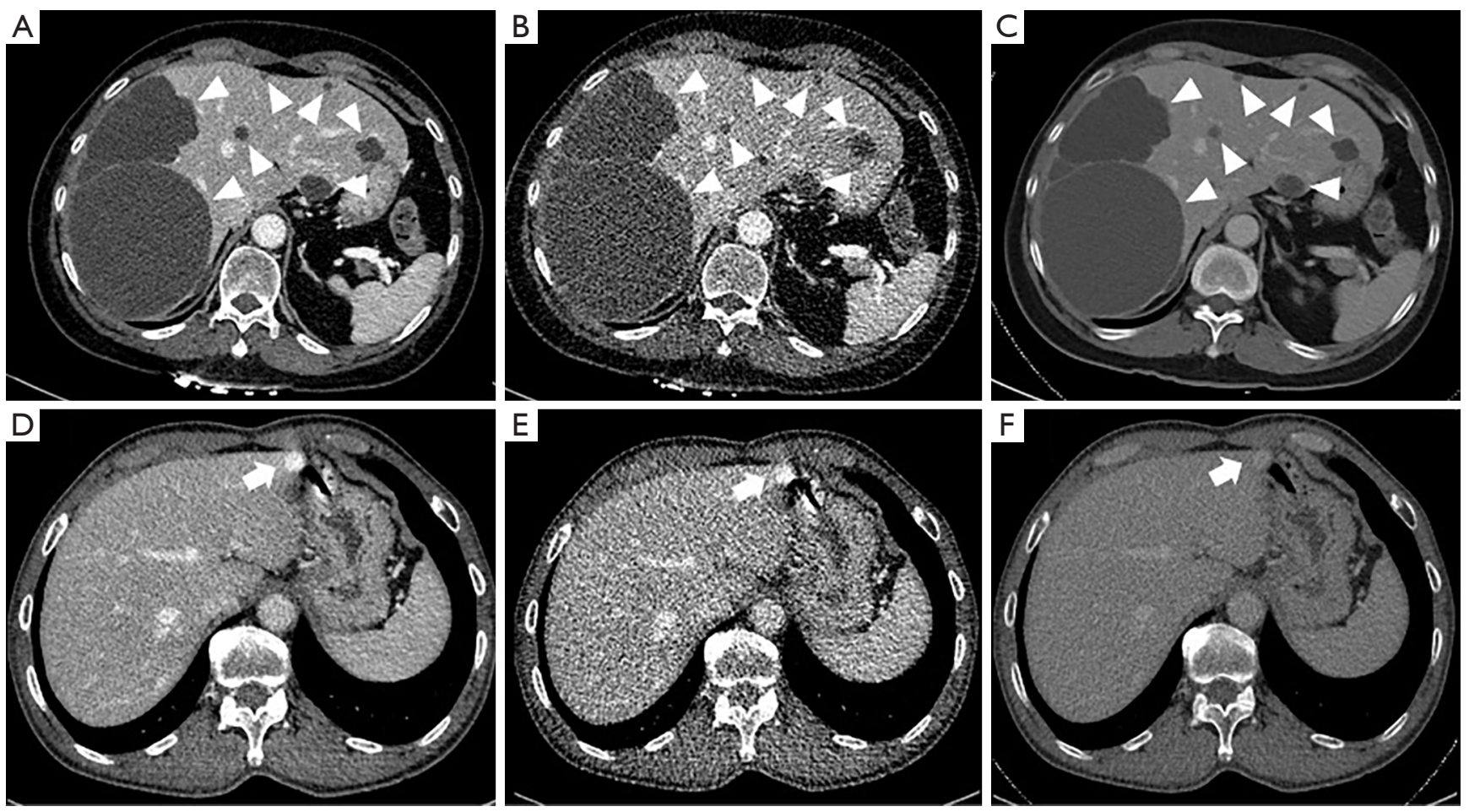

Figure 4 Portal venous phase CT of a 55-year-old female shows hypo-attenuating hepatic cysts (arrowheads) and a hyper-attenuating hepatic hemangioma (arrow), and the images were reconstructed by $50 \mathrm{keV} \mathrm{VMI+} \mathrm{(A,D),} 50$ keV VMI (B,E), and linearly blended (M_0.7, C; M_0.5, F) technique with same window settings (level/width, 150/600). Both types of lesions showed the clearest boundary, highest contrast with surrounding liver tissue, and less noise on the $50 \mathrm{keV} \mathrm{VMI+} \mathrm{images.} \mathrm{VMI,} \mathrm{virtual} \mathrm{monoenergetic} \mathrm{imaging.}$

\section{Pancreatic laceration}

Sugrue et al. (68) examined pancreatic laceration and found the highest CNR and injury-to-normal parenchyma contrast and improved injury conspicuity and diagnostic confidence in $40 \mathrm{keV}$ VMI+ reconstructions. Timely and accurate identification of pancreatic laceration is very important for the treatment and prognosis of patients. Coincidentally, a study using a second-generation DSCT scan followed by VMI+ reconstruction for images of hepatic and splenic lacerations found that the highest CNR also appeared at $40 \mathrm{keV}(69)$.

\section{Spine}

\section{Lumbar internal fixation}

The effect of using the VMI+ technique on reducing metal artifacts generated by lumbar internal fixation was analyzed for the first time by Zeng et al. (70), who found that the $130 \mathrm{keV} \mathrm{VMI}+$ reconstruction for the region surrounding internal fixation could improve the clarity of the metalbone interface and decrease the number of artifacts and facilitate superior diagnostic assessment of the surrounding soft tissue, abdominal aorta, and inferior vena cava. Furthermore, $120 \mathrm{keV}$ VMI+ reconstruction was reportedly appropriate for spinal canal imaging.

In addition to enhanced vessels and tumors, VMI+ has been used in the imaging of children's heads, other liver lesions, pancreatic lacerations, and in reducing metal artifacts. Furthermore, choosing both suitable window settings and a combination of tube voltage according to different abdominal sizes will also improve diagnostic accuracy. The above results, summarized in Table 1, show the optimal energy levels for different lesions to guide clinical application.

\section{Current limitations and future challenges}

The VMI+ technique has been extensively proven to show significantly higher contrast of lesions or vessels containing iodine, lower image noise, and higher image quality than have been VMI and linearly blended reconstructions and SECT images. Moreover, on the premise of using the VMI+ reconstruction, the contrast medium concentrations can 
Table 1 Recommended optimal energy levels for different lesions in studies involving VMI+ technique

\begin{tabular}{|c|c|c|c|c|}
\hline Classification & The focus being examined & $\begin{array}{l}\text { Recommended } \\
\text { energy level }\end{array}$ & Study, year & Supplementary content \\
\hline \multirow[t]{4}{*}{ Tumors } & $\begin{array}{l}\text { Malignant tumor in the } \\
\text { head and neck region; } \\
\text { spinal metastatic tumor; } \\
\text { early gastric cancer }\end{array}$ & 40 keV VMI+ & \multicolumn{2}{|c|}{$\begin{array}{l}\text { May et al., 2017; Albrecht et al. compared the application of } 40 \mathrm{keV} \\
\text { Kraus et al., } \quad \text { and } 55 \mathrm{keV} \mathrm{VMI+} \mathrm{reconstruction} \mathrm{in} \mathrm{head} \mathrm{and} \mathrm{neck} \\
\begin{array}{ll}\text { 2016; Shi et al., } & \text { cancer and recommended } 55 \mathrm{keV} \text {. (Albrecht et al., } \\
2017 & \text { 2015) }\end{array}\end{array}$} \\
\hline & $\begin{array}{l}\text { Head and neck cancer; } \\
\text { lung cancer; hypervascular } \\
\text { liver tumor }\end{array}$ & $55 \mathrm{keV} \mathrm{VMI+}$ & \multicolumn{2}{|l|}{$\begin{array}{l}\text { Albrecht et al., } \\
\text { 2015; Frellesen } \\
\text { et al., 2016; } \\
\text { Marin et al., } \\
2016\end{array}$} \\
\hline & $\begin{array}{l}\text { Renal cell carcinoma in } \\
\text { the nephrogenic phase of } \\
\text { enhancement; } \\
\text { gastrointestinal stromal } \\
\text { tumor; abdominal } \\
\text { metastases; } \\
\text { hypoattenuating liver } \\
\text { metastases from colorectal } \\
\text { cancer }\end{array}$ & $60 \mathrm{keV}$ VMI+ & $\begin{array}{l}\text { Martin et al., } \\
\text { 2017; Martin et } \\
\text { al., 2016; Lenga } \\
\text { et al., 2018 }\end{array}$ & $\begin{array}{l}\text { For hypoattenuating metastases in liver from } \\
\text { colorectal cancer, Lenga recommended } 40 \mathrm{keV} \\
\text { VMI+ as the added energy level for poor contrast } \\
\text { conditions. (Lenga et al., 2018) }\end{array}$ \\
\hline & Pancreatic mass & $\begin{array}{l}40 \mathrm{keV} \text { and } 50 \mathrm{keV} \\
\mathrm{VMI}+\end{array}$ & \multicolumn{2}{|l|}{$\begin{array}{l}\text { Frellesen et al., } \\
2015\end{array}$} \\
\hline \multirow{4}{*}{ Chest } & $\begin{array}{l}\text { Calcified or non-calcified } \\
\text { coronary plaque }\end{array}$ & $\begin{array}{l}\text { Low energy levels } \\
(40-70 \mathrm{keV} \mathrm{VMI}+)\end{array}$ & $\begin{array}{l}\text { Symons et al., } \\
2017\end{array}$ & $\begin{array}{l}\text { When using } 40 \mathrm{keV} \mathrm{VMI}+\text { to reconstruct, } \\
\text { the observers with rich diagnostic experience and } \\
\text { the software with re-calibration could been required. } \\
\text { (Symons et al., 2017) }\end{array}$ \\
\hline & $\begin{array}{l}\text { In-stent of coronary } \\
\text { arteries }\end{array}$ & $\begin{array}{l}\text { High energy levels } \\
(130 \mathrm{keV} \mathrm{VMI}+)\end{array}$ & $\begin{array}{l}\text { Mangold et al., } \\
2016\end{array}$ & \\
\hline & Coronary veins & $\begin{array}{l}\text { The conventional } \\
\text { linearly blended } \\
\text { (M_0.6) } \\
\text { reconstruction }\end{array}$ & Kim et al., 2020 & \\
\hline & Aorta & $\begin{array}{l}\text { Low keV levels ( } 40 \\
\text { keV VMI+) }\end{array}$ & $\begin{array}{l}\text { Beeres et al., } \\
2015\end{array}$ & $\begin{array}{l}\text { Martin et al. recommended } 50 \mathrm{keV} \text { or } 60 \mathrm{keV} \mathrm{VMI}+\text { to } \\
\text { reconstruct for aorta CTA before transcatheter aortic } \\
\text { valve replacement. (Martin et al., 2016) }\end{array}$ \\
\hline
\end{tabular}

Table 1 (continued) 
Table 1 (continued)

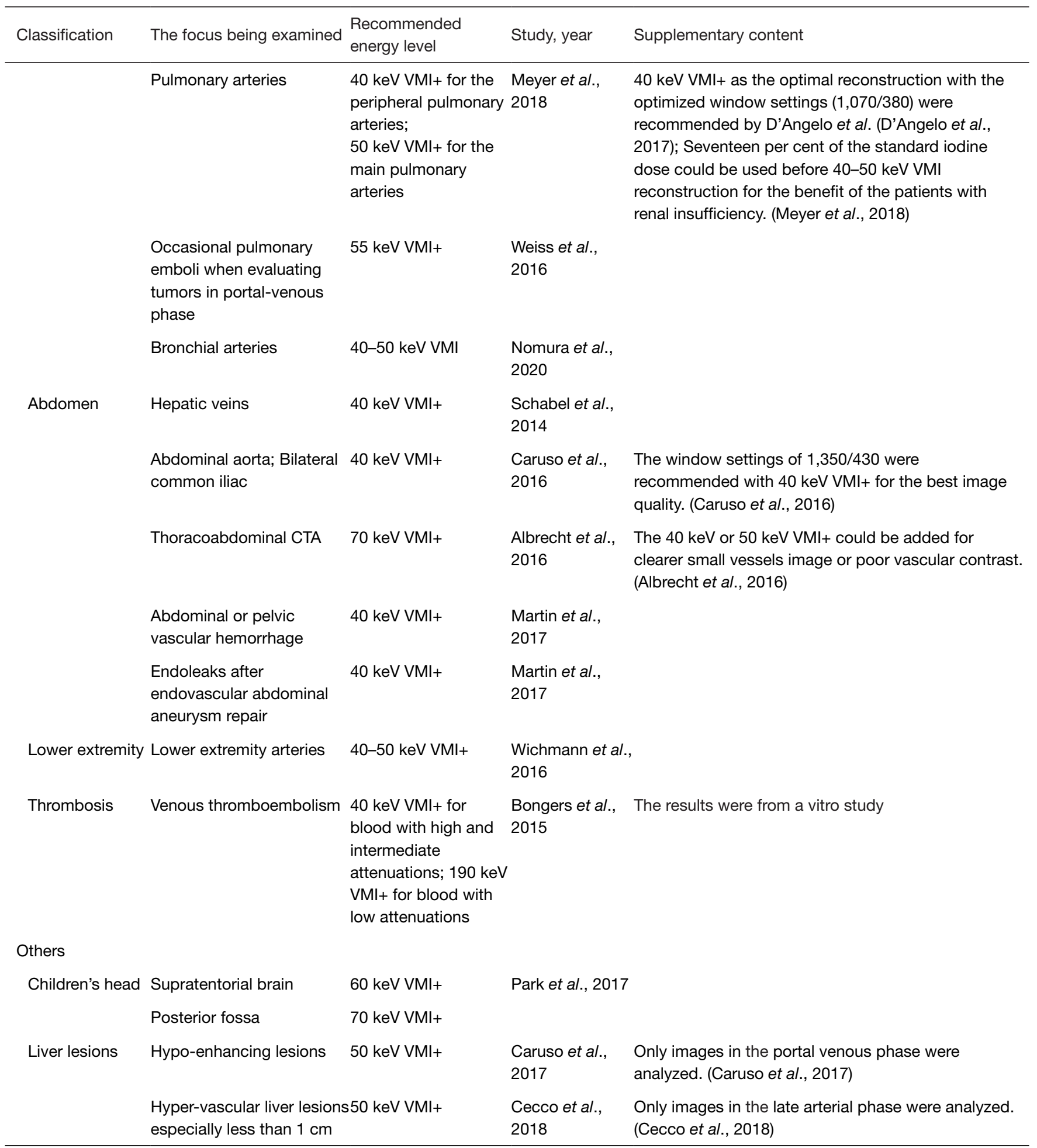

Table 1 (continued) 
Table 1 (continued)

\begin{tabular}{|c|c|c|c|c|}
\hline Classification & The focus being examined & $\begin{array}{l}\text { Recommended } \\
\text { energy level }\end{array}$ & Study, year & Supplementary content \\
\hline & $\begin{array}{l}\text { Liver lesions in hepatic } \\
\text { arterial and portal phases }\end{array}$ & $50 \mathrm{keV}$ VMI+ & $\begin{array}{l}\text { Cecco et al., } \\
2016\end{array}$ & $\begin{array}{l}\text { The recommended window settings were } \\
(429.3 \pm 44.5) /(129.4 \pm 9.7) \text { for lesions in the arterial } \\
\text { phase and }(376.1 \pm 14.6) /(146.6 \pm 7.1) \text { for lesions in the } \\
\text { portal phase. (Cecco et al., 2016) }\end{array}$ \\
\hline $\begin{array}{l}\text { Lumbar internal } \\
\text { fixation }\end{array}$ & $\begin{array}{l}\text { The metal artefact } \\
\text { produced by lumbar } \\
\text { internal fixation }\end{array}$ & $\begin{array}{l}120 \mathrm{keV} \text { and } 130 \mathrm{keV} \\
\text { VMI+ }\end{array}$ & $\begin{array}{l}\text { Zeng et al., } \\
2020\end{array}$ & $\begin{array}{l}\text { The } 130 \mathrm{keV} \text { VMI+ was recommended for } \\
\text { surrounding metal-bone interface, surrounding soft } \\
\text { tissue, abdominal aorta and inferior vena cava; the } \\
120 \mathrm{keV} \mathrm{VMI+} \mathrm{was} \mathrm{recommended} \mathrm{for} \mathrm{the} \mathrm{spinal} \\
\text { canal. (Zeng et al., 2020) }\end{array}$ \\
\hline
\end{tabular}

be decreased to reduce the incidence of contrast-induced nephropathy. However, the VMI+ images are still affected by noise at low energy levels, especially while imaging tumor lesions with relatively low iodine concentrations. Although the CNR of both tumors and vessels is the highest at $40 \mathrm{keV}$, the subjective selection of best quality images is associated with the energy level of $50-60 \mathrm{keV}$. In addition, the VMI+ reconstructions need to be generated on the postprocessing workstation, which is labor-intensive and time-consuming, thus being easily overlooked. Future research should mainly focus on the problem of noise impact on image observation at low energy levels. Because the VMI+ technology involves the reconstruction of two sets of images generated using the high and low energy levels of DECT, the primary breakthrough in reducing the noise of $\mathrm{VMI}+$ images is to reduce the possibility of noise generation by DECT. Because of the unique orthogonal geometry of the two tube-detectors on dual-source DECT, the scattered radiations of the tubes easily affect each other, thus reducing spectral separation and increasing image noise; therefore, a better scatter correction algorithm is needed $(1,2,12)$. In addition, technicians should know the optimal energy level of reconstruction either for the target organs or lesions to improve postprocessing efficiency. Because the $\mathrm{VMI}+$ technology on DECT is a postprocessing technology of the imaging domain, unlike the image processing technology of the projection domain, the VMI+ images can be retrospectively processed after scanning. Therefore, in addition to enhancing tumors, vessels, and organs (brain and liver), other lesions or organs can also be studied. For example, the strong photoelectric effect principle of heavy atoms at low energy could be used to distinguish gallbladder stones containing a small amount of calcium salt from polyps without calcium salt. In solving image quality problems, the image quality can also be further optimized by changing the tube voltage and combining the optimal energy level of $\mathrm{VMI}+$ reconstruction. Additional studies will provide more favorable information regarding imaging diagnosis.

\section{Summary}

The use of DSCT has been steadily increasing. As the postprocessing technology of the third generation DSCT, $\mathrm{VMI}+$ has been widely recognized for reducing image noise, improving image quality, and increasing iodine contrast. Knowing the best energy levels for imaging different lesions is the basis - and even the key-of the VMI+ technique. The reconstructed images, combined with the optimal window settings, provide more accurate information regarding image diagnosis. In addition, the application of VMI+ allows the use of a low concentration of contrast medium and reduces the incidence risk of contrastinduced nephropathy. As a new postprocessing technique, the VMI+ should be explored for applications beyond the reconstructions of vascular or tumor images in the future.

\section{Acknowledgments}

Funding: This study was supported by National Natural Science Foundation of China (No. 81971598, 82071456), Shanghai Shuguang Program (No. 19SG06), Shanghai Municipal Commission of Science and Technology (No. 19411951200). What is more, thanks for the images of renal 
carcinoma (Figure 2) and liver lesions (Figure 4) with the patients' consent provided by the Department of Radiology, Second Xiangya Hospital, Central South University.

\section{Footnote}

Conflicts of Interest: All authors have completed the ICMJE uniform disclosure form (available at https://dx.doi. org/10.21037/qims-20-1196). The authors have no conflicts of interest to declare.

Ethical Statement: The authors are accountable for all aspects of the work in ensuring that questions related to the accuracy or integrity of any part of the work are appropriately investigated and resolved. The informed consent was obtained from the patients for the publication of this manuscript and any accompanying images.

Open Access Statement: This is an Open Access article distributed in accordance with the Creative Commons Attribution-NonCommercial-NoDerivs 4.0 International License (CC BY-NC-ND 4.0), which permits the noncommercial replication and distribution of the article with the strict proviso that no changes or edits are made and the original work is properly cited (including links to both the formal publication through the relevant DOI and the license). See: https://creativecommons.org/licenses/by-nc-nd/4.0/.

\section{References}

1. Forghani R, De Man B, Gupta R. Dual-Energy Computed Tomography: Physical Principles, Approaches to Scanning, Usage, and Implementation: Part 1. Neuroimaging Clin N Am 2017;27:371-84.

2. Goo HW, Goo JM. Dual-Energy CT: New Horizon in Medical Imaging. Korean J Radiol 2017;18:555-69.

3. Yu L, Leng S, McCollough CH. Dual-energy CTbased monochromatic imaging. AJR Am J Roentgenol 2012;199:S9-S15.

4. Grant KL, Flohr TG, Krauss B, Sedlmair M, Thomas C, Schmidt B. Assessment of an advanced image-based technique to calculate virtual monoenergetic computed tomographic images from a dual-energy examination to improve contrast-to-noise ratio in examinations using iodinated contrast media. Invest Radiol 2014;49:586-92.

5. Hounsfield GN. Computerized transverse axial scanning (tomography). 1. Description of system. Br J Radiol 1973;46:1016-22.
6. Alvarez RE, Macovski A. Energy-selective reconstructions in X-ray computerized tomography. Phys Med Biol 1976;21:733-44.

7. Macovski A, Alvarez RE, Chan JL, Stonestrom JP, Zatz LM. Energy dependent reconstruction in $\mathrm{X}$-ray computerized tomography. Comput Biol Med 1976;6:325-36.

8. Chiro GD, Brooks RA, Kessler RM, Johnston GS, Jones AE, Herdt JR, Sheridan WT. Tissue signatures with dualenergy computed tomography. Radiology 1979;131:521-3.

9. Genant HK, Boyd D. Quantitative bone mineral analysis using dual energy computed tomography. Invest Radiol 1977;12:545-51.

10. Kelcz F, Joseph PM, Hilal SK. Noise considerations in dual energy CT scanning. Med Phys 1979;6:418-25.

11. Millner MR, McDavid WD, Waggener RG, Dennis MJ, Payne WH, Sank VJ. Extraction of information from CT scans at different energies. Med Phys 1979;6:70-1.

12. McCollough CH, Leng S, Yu L, Fletcher JG. Dual- and Multi-Energy CT: Principles, Technical Approaches, and Clinical Applications. Radiology 2015;276:637-53.

13. Primak AN, Ramirez Giraldo JC, Liu X, Yu L, McCollough CH. Improved dual-energy material discrimination for dual-source CT by means of additional spectral filtration. Med Phys 2009;36:1359-69.

14. Patel BN, Marin D. Strategies to Improve Image Quality on Dual-Energy Computed Tomography. Radiol Clin North Am 2018;56:641-7.

15. Krauss B. Dual-Energy Computed Tomography: Technology and Challenges. Radiol Clin North Am 2018;56:497-506.

16. Parakh A, Macri F, Sahani D. Dual-Energy Computed Tomography: Dose Reduction, Series Reduction, and Contrast Load Reduction in Dual-Energy Computed Tomography. Radiol Clin North Am 2018;56:601-24.

17. Yu L, Bruesewitz MR, Thomas KB, Fletcher JG, Kofler JM, McCollough CH. Optimal tube potential for radiation dose reduction in pediatric CT: principles, clinical implementations, and pitfalls. Radiographics 2011;31:835-48.

18. Delesalle MA, Pontana F, Duhamel A, Faivre JB, Flohr T, Tacelli N, Remy J, Remy-Jardin M. Spectral optimization of chest CT angiography with reduced iodine load: experience in 80 patients evaluated with dual-source, dualenergy CT. Radiology 2013;267:256-66.

19. Martin SS, Wichmann JL, Pfeifer S, Leithner D, Lenga L, Reynolds MA, D'Angelo T, Hammerstingl R, GruberRouh T, Vogl TJ, Albrecht MH. Impact of noise- 
optimized virtual monoenergetic dual-energy computed tomography on image quality in patients with renal cell carcinoma. Eur J Radiol 2017;97:1-7.

20. Martin SS, Wichmann JL, Weyer H, Albrecht MH, D'Angelo T, Leithner D, Lenga L, Booz C, Scholtz JE, Bodelle B, Vogl TJ, Hammerstingl R. Dual-energy computed tomography in patients with cutaneous malignant melanoma: Comparison of noise-optimized and traditional virtual monoenergetic imaging. Eur J Radiol 2017;95:1-8.

21. Albrecht MH, Scholtz JE, Kraft J, Bauer RW, Kaup M, Dewes P, Bucher AM, Burck I, Wagenblast J, Lehnert T, Kerl JM, Vogl TJ, Wichmann JL. Assessment of an Advanced Monoenergetic Reconstruction Technique in Dual-Energy Computed Tomography of Head and Neck Cancer. Eur Radiol 2015;25:2493-501.

22. Frellesen C, Kaup M, Wichmann JL, Hüsers K, Scholtz JE, Albrecht MH, Metzger SC, Bauer RW, Kerl JM, Lehnert T, Vogl TJ, Bodelle B. Noise-optimized advanced image-based virtual monoenergetic imaging for improved visualization of lung cancer: Comparison with traditional virtual monoenergetic imaging. Eur J Radiol 2016;85:665-72.

23. Marin D, Ramirez-Giraldo JC, Gupta S, Fu W, Stinnett SS, Mileto A, Bellini D, Patel B, Samei E, Nelson RC. Effect of a Noise-Optimized Second-Generation Monoenergetic Algorithm on Image Noise and Conspicuity of Hypervascular Liver Tumors: An In Vitro and In Vivo Study. AJR Am J Roentgenol 2016;206:1222-32.

24. Martin SS, Pfeifer S, Wichmann JL, Albrecht MH, Leithner D, Lenga L, Scholtz JE, Vogl TJ, Bodelle B. Noise-optimized virtual monoenergetic dual-energy computed tomography: optimization of kiloelectron volt settings in patients with gastrointestinal stromal tumors. Abdom Radiol (NY) 2017;42:718-26.

25. Lenga L, Czwikla R, Wichmann JL, Leithner D, Albrecht MH, Booz C, Arendt CT, Yel I, D'Angelo T, Vogl TJ, Martin SS. Dual-energy CT in patients with colorectal cancer: Improved assessment of hypoattenuating liver metastases using noise-optimized virtual monoenergetic imaging. Eur J Radiol 2018;106:184-91.

26. Frellesen C, Fessler F, Hardie AD, Wichmann JL, De Cecco CN, Schoepf UJ, Kerl JM, Schulz B, Hammerstingl R, Vogl TJ, Bauer RW. Dual-energy CT of the pancreas: improved carcinoma-to-pancreas contrast with a noiseoptimized monoenergetic reconstruction algorithm. Eur J Radiol 2015;84:2052-8.

27. Kraus M, Weiss J, Selo N, Flohr T, Notohamiprodjo
M, Bamberg F, Nikolaou K, Othman AE. Spinal dualenergy computed tomography: improved visualisation of spinal tumorous growth with a noise-optimised advanced monoenergetic post-processing algorithm. Neuroradiology 2016;58:1093-102.

28. May MS, Bruegel J, Brand M, Wiesmueller M, Krauss B, Allmendinger T, Uder M, Wuest W. Computed Tomography of the Head and Neck Region for Tumor Staging-Comparison of Dual-Source, Dual-Energy and Low-Kilovolt, Single-Energy Acquisitions. Invest Radiol 2017;52:522-8.

29. Shi C, Zhang H, Yan J, Wang B, Du L, Pan Z, Yan F. Decreased stage migration rate of early gastric cancer with a new reconstruction algorithm using dual-energy CT images: a preliminary study. Eur Radiol 2017;27:671-80.

30. May MS, Wiesmueller M, Heiss R, Brand M, Bruegel J, Uder M, Wuest W. Comparison of dual- and single-source dual-energy CT in head and neck imaging. Eur Radiol 2019;29:4207-14.

31. Leithner D, Mahmoudi S, Wichmann JL, Martin SS, Lenga L, Albrecht MH, Booz C, Arendt CT, Beeres M, D'Angelo T, Bodelle B, Vogl TJ, Scholtz JE. Evaluation of virtual monoenergetic imaging algorithms for dual-energy carotid and intracerebral CT angiography: Effects on image quality, artefacts and diagnostic performance for the detection of stenosis. Eur J Radiol 2018;99:111-7.

32. Riffel P, Haubenreisser H, Meyer M, Sudarski S, Morelli JN, Schmidt B, Schoenberg SO, Henzler T. Carotid dualenergy CT angiography: Evaluation of low keV calculated monoenergetic datasets by means of a frequency-split approach for noise reduction at low keV levels. Eur J Radiol 2016;85:720-5.

33. Zhao L, Li F, Zhang Z, Zhang Z, Jiang Y, Wang X, Gu J, $\mathrm{Li} \mathrm{D}$. Assessment of an advanced virtual monoenergetic reconstruction technique in cerebral and cervical angiography with third-generation dual-source CT: Feasibility of using low-concentration contrast medium. Eur Radiol 2018;28:4379-88.

34. Arendt CT, Czwikla R, Lenga L, Wichmann JL, Albrecht MH, Booz C, Martin SS, Leithner D, Tischendorf P, Blandino A, Vogl TJ, D'Angelo T. Improved coronary artery contrast enhancement using noise-optimised virtual monoenergetic imaging from dual-source dual-energy computed tomography. Eur J Radiol 2020;122:108666.

35. Symons R, Choi Y, Cork TE, Ahlman MA, Mallek M, Bluemke DA, Sandfort V. Optimized energy of spectral coronary CT angiography for coronary plaque detection and quantification. J Cardiovasc Comput Tomogr 
2018;12:108-14.

36. Mahnken AH. CT Imaging of Coronary Stents: Past, Present, and Future. ISRN Cardiol 2012;2012:139823.

37. Mangold S, Cannaó PM, Schoepf UJ, Wichmann JL, Canstein C, Fuller SR, Muscogiuri G, Varga-Szemes A, Nikolaou K, De Cecco CN. Impact of an advanced image-based monoenergetic reconstruction algorithm on coronary stent visualization using third generation dualsource dual-energy CT: a phantom study. Eur Radiol 2016;26:1871-8.

38. Taylor AJ, Cerqueira M, Hodgson JM, Mark D, Min J, O'Gara P, Rubin GD; Society for Cardiovascular Magnetic Resonance. ACCF/SCCT/ACR/AHA/ASE/ASNC/ NASCI/SCAI/SCMR 2010 Appropriate Use Criteria for Cardiac Computed Tomography. A Report of the American College of Cardiology Foundation Appropriate Use Criteria Task Force, the Society of Cardiovascular Computed Tomography, the American College of Radiology, the American Heart Association, the American Society of Echocardiography, the American Society of Nuclear Cardiology, the North American Society for Cardiovascular Imaging, the Society for Cardiovascular Angiography and Interventions, and the Society for Cardiovascular Magnetic Resonance. J Cardiovasc Comput Tomogr 2010;4:407.e1-33.

39. De Santis D, Caruso D, Schoepf UJ, Eid M, Albrecht MH, Duguay TM, Varga-Szemes A, Laghi A, De Cecco $\mathrm{CN}$. Contrast media injection protocol optimization for dual-energy coronary CT angiography: results from a circulation phantom. Eur Radiol 2018;28:3473-81.

40. Kim GM, Choo KS, Kim JH, Hwang JY, Park CK, Lee JW, Lim SJ. Comparison of noise-optimized linearly blended images and noise-optimized virtual monoenergetic images evaluated by dual-source, dual-energy CT in cardiac vein assessment. Acta Radiol 2021;62:594-602.

41. Beeres M, Trommer J, Frellesen C, Nour-Eldin NE, Scholtz JE, Herrmann E, Vogl TJ, Wichmann JL. Evaluation of different keV-settings in dual-energy CT angiography of the aorta using advanced image-based virtual monoenergetic imaging. Int J Cardiovasc Imaging 2016;32:137-44.

42. Martin SS, Albrecht MH, Wichmann JL, Hüsers K, Scholtz JE, Booz C, Bodelle B, Bauer RW, Metzger SC, Vogl TJ, Lehnert T. Value of a noise-optimized virtual monoenergetic reconstruction technique in dual-energy CT for planning of transcatheter aortic valve replacement. Eur Radiol 2017;27:705-14.

43. Meier A, Wurnig M, Desbiolles L, Leschka S, Frauenfelder
T, Alkadhi H. Advanced virtual monoenergetic images: improving the contrast of dual-energy CT pulmonary angiography. Clin Radiol 2015;70:1244-51.

44. Meyer M, Haubenreisser H, Schabel C, Leidecker C, Schmidt B, Schoenberg SO, Henzler T. CT pulmonary angiography in patients with acute or chronic renal insufficiency: Evaluation of a low dose contrast material protocol. Sci Rep 2018;8:1995.

45. Weiss J, Notohamiprodjo M, Bongers M, Schabel C, Mangold S, Nikolaou K, Bamberg F, Othman AE. Noiseoptimized monoenergetic post-processing improves visualization of incidental pulmonary embolism in cancer patients undergoing single-pass dual-energy computed tomography. Radiol Med 2017;122:280-7.

46. Weiss J, Notohamiprodjo M, Bongers M, Schabel C, Mangold S, Nikolaou K, Bamberg F, Othman AE. Effect of Noise-Optimized Monoenergetic Postprocessing on Diagnostic Accuracy for Detecting Incidental Pulmonary Embolism in Portal-Venous Phase Dual-Energy Computed Tomography. Invest Radiol 2017;52:142-7.

47. D'Angelo T, Bucher AM, Lenga L, Arendt CT, Peterke JL, Caruso D, Mazziotti S, Blandino A, Ascenti G, Othman AE, Martin SS, Leithner D, Vogl TJ, Wichmann JL. Optimisation of window settings for traditional and noise-optimised virtual monoenergetic imaging in dualenergy computed tomography pulmonary angiography. Eur Radiol 2018;28:1393-401.

48. Nomura T, Niwa T, Ozawa S, Imai Y, Hashimoto J. Visibility of bronchial arteries using virtual and advanced virtual monoenergetic imaging. Acta Radiol 2020;61:1618-27.

49. Schabel C, Bongers M, Sedlmair M, Korn A, Grosse U, Mangold S, Claussen CD, Thomas C. Assessment of the hepatic veins in poor contrast conditions using dual energy CT: evaluation of a novel monoenergetic extrapolation software algorithm. Rofo 2014;186:591-7.

50. Albrecht MH, Scholtz JE, Hüsers K, Beeres M, Bucher AM, Kaup M, Martin SS, Fischer S, Bodelle B, Bauer RW, Lehnert T, Vogl TJ, Wichmann JL. Advanced imagebased virtual monoenergetic dual-energy CT angiography of the abdomen: optimization of kiloelectron volt settings to improve image contrast. Eur Radiol 2016;26:1863-70.

51. Albrecht MH, Trommer J, Wichmann JL, Scholtz JE, Martin SS, Lehnert T, Vogl TJ, Bodelle B. Comprehensive Comparison of Virtual Monoenergetic and Linearly Blended Reconstruction Techniques in Third-Generation Dual-Source Dual-Energy Computed Tomography Angiography of the Thorax and Abdomen. Invest Radiol 
2016;51:582-90.

52. Martin SS, Wichmann JL, Scholtz JE, Leithner D, D'Angelo T, Weyer H, Booz C, Lenga L, Vogl TJ, Albrecht MH. Noise-Optimized Virtual Monoenergetic Dual-Energy CT Improves Diagnostic Accuracy for the Detection of Active Arterial Bleeding of the Abdomen. J Vasc Interv Radiol 2017;28:1257-66.

53. Caruso D, Parinella AH, Schoepf UJ, Stroebel MH, Mangold S, Wichmann JL, Varga-Szemes A, Ball BD Jr, De Santis D, Laghi A, De Cecco CN. Optimization of window settings for standard and advanced virtual monoenergetic imaging in abdominal dual-energy CT angiography. Abdom Radiol (NY) 2017;42:772-80.

54. Wichmann JL, Gillott MR, De Cecco CN, Mangold S, Varga-Szemes A, Yamada R, Otani K, Canstein C, Fuller SR, Vogl TJ, Todoran TM, Schoepf UJ. Dual-Energy Computed Tomography Angiography of the Lower Extremity Runoff: Impact of Noise-Optimized Virtual Monochromatic Imaging on Image Quality and Diagnostic Accuracy. Invest Radiol 2016;51:139-46.

55. Harris PL, Vallabhaneni SR, Desgranges P, Becquemin JP, van Marrewijk C, Laheij RJ. Incidence and risk factors of late rupture, conversion, and death after endovascular repair of infrarenal aortic aneurysms: the EUROSTAR experience. European Collaborators on Stent/graft techniques for aortic aneurysm repair. J Vasc Surg 2000;32:739-49.

56. Martin SS, Wichmann JL, Weyer H, Scholtz JE, Leithner D, Spandorfer A, Bodelle B, Jacobi V, Vogl TJ, Albrecht MH. Endoleaks after endovascular aortic aneurysm repair: Improved detection with noiseoptimized virtual monoenergetic dual-energy CT. Eur J Radiol 2017;94:125-32.

57. Silverstein MD, Heit JA, Mohr DN, Petterson TM, O'Fallon WM, Melton LJ 3rd. Trends in the incidence of deep vein thrombosis and pulmonary embolism: a 25-year population-based study. Arch Intern Med 1998;158:585-93.

58. Fobbe F, Ruhnke-Trautmann M, von Gemmeren D, Hartmann CA, Kania U, Wolf KJ. Age determination of venous thrombi by ultrasound. Rofo 1991;155:344-8.

59. Geier B, Barbera L, Muth-Werthmann D, Siebers S, Ermert H, Philippou S, Mumme A. Ultrasound elastography for the age determination of venous thrombi. Evaluation in an animal model of venous thrombosis. Thromb Haemost 2005;93:368-74.

60. De Luca F, Modolon C, Buia F, Attinà D, Fughelli P, Bacchi Reggiani ML, Galiè N, Zompatori M.
Densitometric CT evaluation of acute and chronic thromboembolic filling defects of the pulmonary arteries before and after contrast injection. Radiol Med 2012;117:979-91.

61. Bongers MN, Schabel C, Krauss B, Tsiflikas I, Ketelsen D, Mangold S, Claussen CD, Nikolaou K, Thomas C. Noise-optimized virtual monoenergetic images and iodine maps for the detection of venous thrombosis in secondgeneration dual-energy CT (DECT): an ex vivo phantom study. Eur Radiol 2015;25:1655-64.

62. Park J, Choi YH, Cheon JE, Kim WS, Kim IO, Pak SY, Krauss B. Advanced virtual monochromatic reconstruction of dual-energy unenhanced brain computed tomography in children: comparison of image quality against standard mono-energetic images and conventional polychromatic computed tomography. Pediatr Radiol 2017;47:1648-58.

63. Michalak G, Grimes J, Fletcher J, Halaweish A, Yu L, Leng S, McCollough C. Selection of optimal tube potential settings for dual-energy CT virtual monoenergetic imaging of iodine in the abdomen. Abdom Radiol (NY) 2017;42:2289-96.

64. Husarik DB, Gordic S, Desbiolles L, Krauss B, Leschka S, Wildermuth S, Alkadhi H. Advanced virtual monoenergetic computed tomography of hyperattenuating and hypoattenuating liver lesions: ex-vivo and patient experience in various body sizes. Invest Radiol 2015;50:695-702.

65. Caruso D, De Cecco CN, Schoepf UJ, Schaefer AR, Leland PW, Johnson D, Laghi A, Hardie AD. Can dualenergy computed tomography improve visualization of hypoenhancing liver lesions in portal venous phase? Assessment of advanced image-based virtual monoenergetic images. Clin Imaging 2017;41:118-24.

66. De Cecco CN, Caruso D, Schoepf UJ, De Santis D, Muscogiuri G, Albrecht MH, Meinel FG, Wichmann JL, Burchett PF, Varga-Szemes A, Sheafor DH, Hardie AD. A noise-optimized virtual monoenergetic reconstruction algorithm improves the diagnostic accuracy of late hepatic arterial phase dual-energy CT for the detection of hypervascular liver lesions. Eur Radiol 2018;28:3393-404.

67. De Cecco CN, Caruso D, Schoepf UJ, Wichmann JL, Ter Louw JR, Perry JD, Picard MM, Schaefer AR, Parker LW, Hardie AD. Optimization of window settings for virtual monoenergetic imaging in dual-energy CT of the liver: A multi-reader evaluation of standard monoenergetic and advanced imaged-based monoenergetic datasets. Eur J Radiol 2016;85:695-9.

68. Sugrue G, Walsh JP, Zhang Y, Niu B, Macri F, Khasanova 
E, Metwally O, Murray N, Nicolaou S. Virtual monochromatic reconstructions of dual energy CT in abdominal trauma: optimization of energy level improves pancreas laceration conspicuity and diagnostic confidence. Emerg Radiol 2021;28:1-7.

69. Sun EX, Wortman JR, Uyeda JW, Lacson R, Sodickson AD. Virtual monoenergetic dual-energy CT for evaluation of hepatic and splenic lacerations. Emerg Radiol 2019;26:419-25.

70. Zeng Y, Deng K, Yang H, Tan Y, Liu J, Geng D, Zhang J. Noise-optimised virtual monoenergetic imaging of dual-energy CT: effect on metal artefact reduction in patients with lumbar internal fixation. Eur Spine J 2019;28:1783-92.

Cite this article as: Zeng Y, Geng D, Zhang J. Noiseoptimized virtual monoenergetic imaging technology of the third-generation dual-source computed tomography and its clinical applications. Quant Imaging Med Surg 2021;11(11):46274643. doi: 10.21037/qims-20-1196 